\title{
Effect of multiple cervical facet joint intra-articular steroid injection for early mobilization of cervical spine in early cervical predominant ankylosing spondylitis
}

\author{
Mohammad Moniruzzaman ${ }^{1}$, Md. Shahadat Hossain², Muhammad Alamgir Mandal ${ }^{3}$, \\ Md. Zakir Hossain ${ }^{4}$, Md. Ahsan Ullah ${ }^{5}$, Syed Mozaffar Ahmed ${ }^{6}$
}

\begin{abstract}
Background: Ankylosing spondylitis (AS) have also been described as causes of facet joint pain. Image-guided injection of local anesthetic and steroid into the facet joint aims to break this vicious cycle and stop the inflammatory reaction involving facet joints in AS. Objectives: Image-guided injection of local anesthetic and steroid into the facet joint aims to break this vicious cycle and stop the inflammatory reaction involving facet joints in AS. Materials \& Methods: Obtaining an informed consent, the procedure was performed with strict aseptic precautions and intra-procedural vital parameters were monitored. Results: After 7 days of extensive rehabilitation program, the ROM in all direction was dramatically improved with significant improvement of pain. Regarding VAS, during 1 st visit it was 8 , after 30 min of injection the score became 6 (25\% improvement) and after one week, the score became 2 (75\% improvement). Conclusion: Multiple intra-articular cervical facet joint steroid injection is very much effective in acute facet joint synovitis in cervical predominant early AS for starting early rehabilitation program.
\end{abstract}

Keywords: AS, Cervical facet joint, Intra-articular steroid injection.

Date of received: 01. 11. 2017

Date of acceptance: 05. 01.2018

\section{Inroduction}

Ankylosing spondylitis (AS) have also been described as causes of facet joint pain. ${ }^{1}$ Image-guided injection of local anesthetic and steroid into the facet joint aims to break this vicious cycle and stop the inflammatory reaction involving facet joints in $\mathrm{AS}^{2}$.

\section{Case Report}

A 23 old male, nonsmoker, normotensive, nondiabetic with the complaints of acute inflammatory type of neck pain for 2 months with severely restricted neck movement was reported on August, 2014.

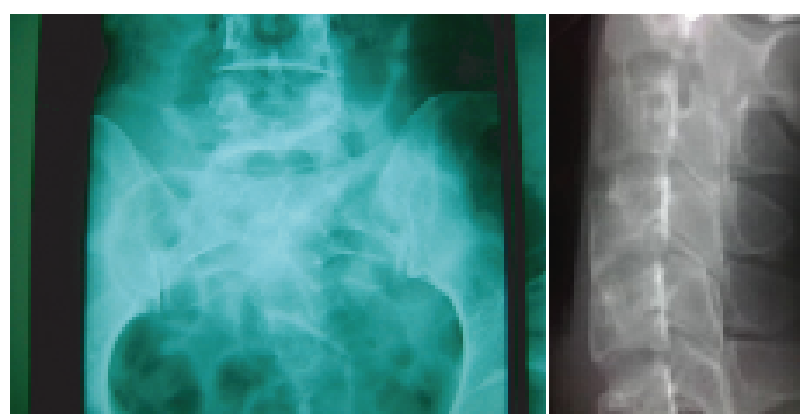

Figure 1
Figure 2

1. Assistant Professor, Department of Physical Medicine \& Rehabilitation, Dhaka Medical College, Dhaka, Bangladesh.

2. Associate Professor, Department of Physical Medicine \& Rehabilitation, Dhaka Medical College, Dhaka, Bangladesh.

3. Assistant Professor \& Head, Department of Physical Medicine \& Rehabilitation, Khwaja Yunus Ali Medical College \& Hospital, Sirajgonj, Bangladesh.

4. Professor \& Head, Department of Medicine \& Principal of Rangpur Medical College, Rnagpur, Bangladesh.

5. Associate Professor, Department of Physical Medicine \& Rehabilitation, Bangabandhu Sheikh Mujib Medical University, Dhaka, Bangladesh.

6. Professor, Department of Physical Medicine \& Rehabilitation, Bangabandhu Sheikh Mujib Medical University, Dhaka, Bangladesh.

Correspondence: Dr. Muhammad Alamgir Mandal, Assistant Professor \& Head, Department of Physical Medicine \& Rehabilitation, Khwaja Yunus Ali Medical College \& Hospital, Enayetpur, Sirajgonj, Bangladesh. Phone: $+8801712-930016$, e-mail: dralam00@yahoo.com 


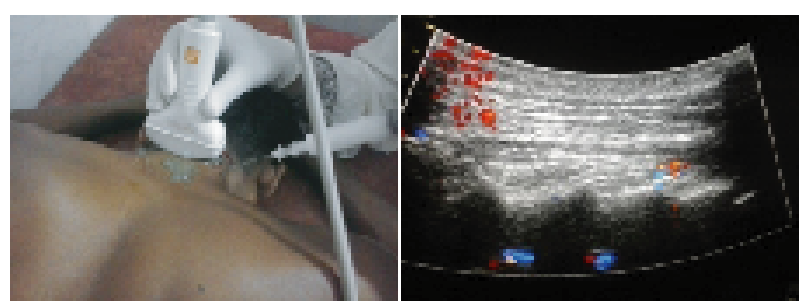

Figure 3

Regarding MSK examination, neck flexion-00, extension-100, left lateral flexion-50, right sided rotation-150, left sided roation-300, grade-III tenderness in bilateral cervical facet joints, VAS score- 8 , modified schober test- $5 \mathrm{~cm}$, both sacroilliac joints gr-1 tenderness with no enthesitis. Regarding investigations, ESR-78 mm Hg, CRP-48, HLA-B-27-positive, $\mathrm{X}$-ray of pelvis showed gr-I bilateral sacroillitis (Figure 1) and X-ray of cervical spine (CS) showed syndesmophyte in $\mathrm{C} 2 / \mathrm{C} 3, \mathrm{C} 3 / \mathrm{C} 4, \mathrm{C} 4 / \mathrm{C} 5$ but no bamboo spine (Figure 2) . He was advised to take Ultrasono-guided Intra-articular cervical facet joint steroid injections successfully followed by physical therapy for acute pain relief $\&$ early mobilization of cervical spine. He also advised to start sulfasalazine with Indomethacin.

\section{Intra-Articular Cervical Facet Joint Injections}

Obtaining an informed consent, the procedure was performed with strict aseptic precautions and intra-procedural vital parameters were monitored. A high resolution ultrasound GE Healthcare Vivid 7 pro (USA) with $7 \mathrm{mhz}$ probe was used. $0.5 \mathrm{cc}$ injectate $(10 \mathrm{mg}$ methy prednisolone: $0.1 \mathrm{cc} 2 \%$ lignocaine, $0.3 \mathrm{cc}$ normal saline) was given in bilateral $\mathrm{C} 3 / 4$, $\mathrm{C} 4 / 5, \mathrm{C} 5 / 6, \mathrm{C} 6 / 7$ facet joints (Figure 3).

\section{Results}

After 7 days of extensive rehabilitation program, his ROM in all direction was dramatically improved with significant improvement of pain. Regarding VAS, during 1st visit it was 8 , after $30 \mathrm{~min}$ of injection the score became $6(25 \%$ improvement) and after one week, the score became $2(75 \%$ improvement). Table I shows, improvement of ROM of cervical spine after intervention, which is shown in Figure $4,5,6,7$.

Table I : ROM of cervical spine

\begin{tabular}{|c|c|c|c|c|c|c|}
\hline & Flexion & xtension* & $\begin{array}{l}\text { Right } \\
\text { lateral } \\
\text { flexion* }\end{array}$ & $\begin{array}{c}\text { Left } \\
\text { lateral } \\
\text { flexion* }\end{array}$ & $\begin{array}{l}\text { Right } \\
\text { sided } \\
\text { rotation * }\end{array}$ & $\begin{array}{c}\text { Left } \\
\text { sided } \\
\text { Rotation * }\end{array}$ \\
\hline 1st Visit & $0^{0}$ & $10^{0}$ & $-5^{0}$ & $5^{0}$ & $\begin{array}{r}0 \\
15\end{array}$ & $30^{\circ}$ \\
\hline 2nd Visit & $30^{0}$ & $40^{0}$ & $\begin{array}{r}0 \\
15\end{array}$ & $\begin{array}{r}0 \\
15\end{array}$ & $40^{0}$ & $70^{0}$ \\
\hline $\begin{array}{l}\text { Improvement } \\
\text { in degree }\end{array}$ & $30^{\circ}$ & $30^{\circ}$ & $20^{\circ}$ & $10^{0}$ & $\begin{array}{r}0 \\
25\end{array}$ & $40^{\circ}$ \\
\hline $\begin{array}{l}\text { Improvement } \\
\text { in percentage }\end{array}$ & 37.5 & 60 & 44.44 & 22.22 & 3125 & 50 \\
\hline
\end{tabular}

(*) ROM measured by universal half-circle goniometer.

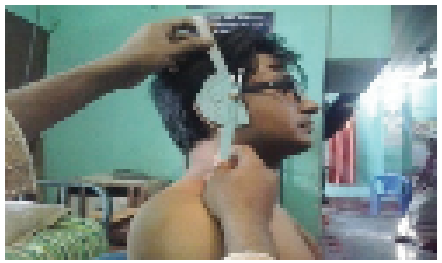

Figure 4

Extension before

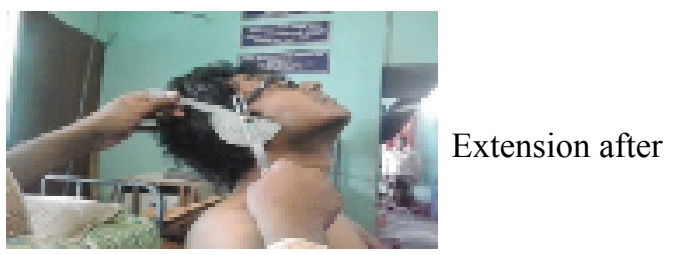

Figure 5

Figure 4: Shows Flexion of neck before and figure no. 5 shows Flexion of neck after intra-articular facet joint steroid injection.

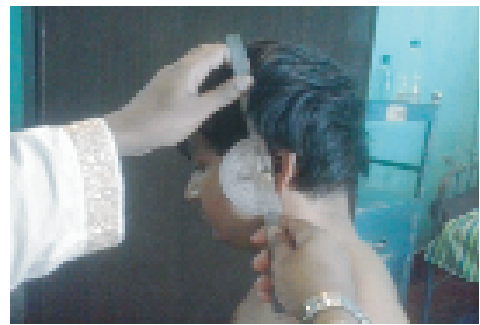

Flexion before

Figure 6

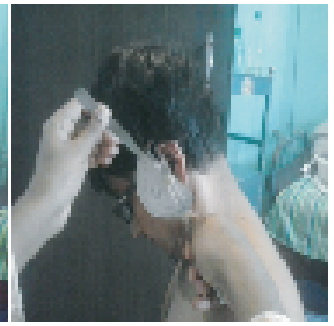

Flexion after
Figure 6: Shows Extension of neck before and figure no. 7 shows Extension of neck after intra-articular facet joint steroid injection.

\section{Discussion}

Among all ROM, highest ROM achieved in extension, lowest in left lateral flexion. The anaesthetic is probably responsible for immediate pain relief whereas steroids are believed to be responsible for pain relief 2-6 days after their administration ${ }^{3}$. In conjunction with NSAID, DMARD \& extensive rehabilitation program, quick restoration of $\mathrm{ROM}$ and maintenance of CS mobilization will be better otherwise most of the cervical predominant AS cases seems to be quick turn to ankylosis without bony ankylosis in early stage.

\section{Conclusion}

Multiple intra-articular cervical facet joint steroid injection is very much effective in acute facet joint synovitis in cervical predominant early AS for starting early rehabilitation program.

\section{Acknowledgements}

We are extremely grateful to Prof. Dr. Mohammad Moyeenuzzaman, Professor, Department of Physical Medicine \& Rehabilitation, Bangabandhu Sheikh Mujib Medical University, Dhaka. It is our great pleasure to express our regards to all the staffs of popular diagnostic center, Dhaka for their endless support during the study period.

\section{References}

1. Bogduk N. Clinical Anatomy of the Lumbar Spine and Sacrum. Ed 3. New York: Churchill Livingstone; 1997. Low back pain;pp.187-214.

2. Ronald Mcrae, Clinical Orthopaedic Examination, Ed 6, Chuchill Livingstone, Elseiver. 2010.

3. Hession WG, Stanczak JD, Davis KW, Choi JJ. Epidural steroid injections. Semin Roentgenol. 2004;39:7-23. 